\title{
Cognitive dictionary structure of the elderly
}

\author{
JON D. SWARTZ \\ Southwestern University, Georgetown, Texas 78626 \\ LOUIS J. MORAN \\ University of British Columbia, Vancouver, British Columbia V6T IW5, Canada \\ and \\ CHARLES C. CLELAND \\ Department of Educational Psychology, University of Texas, Austin, Texas 78712
}

\begin{abstract}
An 80-word free word association list was administered individually to a sample of elderly men and women on two occasions, 1 week apart. Elderly persons were found to exhibit the same enduring free word association response sets (the tendency to give a predominance of one or another specific class of associate; e.g., contrast) found in earlier studies of children. Although the response sets of the elderly were reliable, as was found in studies of younger persons, the majority of their specific word pairs were different. It was concluded that individual differences in cognitive dictionaries of the elderly are represented better by hierarchies of association principles that differ in probability of use than by hierarchies of specific word-word affinities.
\end{abstract}

In an earlier study, the durability of characteristic response sets in free word associations of children from age 9 to 17 years was established (Moran \& Swartz, 1970). The three different response sets (a tendency to give a predominance of either contrasting or defining or predication word associates) seemed to become stronger (more predictable) in the same children over time. The authors concluded that the "structures of cognitive dictionaries become more inflexible with age" (Moran \& Swartz, 1970, p. 25). The present study afforded an opportunity to determine the stability and predictability of these response sets in elderly people.

\section{METHOD}

\section{Subjects}

The subjects were 25 women and 7 men who might easily qualify as surrogate grandparents or great-grandparents of the children in the earlier study. They were middle-class, white, English-speaking residents of Texas communities who represent the dominant values in the southwestern U.S. today. One subject was 55 years old, 12 were in their $60 \mathrm{~s}, 13$ in their 70 s, and 6 in their 80 s. Their average age was 72 years.

\section{Procedure}

The 80-word list (Moran, 1966) used in the earlier study was administered individually on two occasions, 1 week apart. The same scoring manual was used to score responses for the following three variables: (1) dimension-referent-summation of contrast (dark-light) and coordinate (blue-yellow, apple-orange) word pairs; (2) perceptual-referent-summation of sensory

The authors wish to thank Keith F. Bell and Madeline D. Norwood for their assistance. Requests for reprints should be sent to Jon D. Swartz, Mood-Bridwell Hall 232, Southwestern University, Georgetown, Texas 78626. predicates (yellow-banana, oil-hot) and abstract predicates (long-day, eagle-bold); (3) concept-referent-summation of synonym (small-little) and superordinate (cabbage-vegetable) word pairs.

Separate arrays of $\mathrm{z}$ scores were calculated for first and second testings of the sample. As in the earlier study employing children, the criteria on first testing for a specific response set were a $\mathrm{z}$ score above .50 on one of the three variables and $\mathrm{z}$ scores below .50 on the other two variables. In this manner, 12 of the elderly were labeled dimension-referent, 4 perceptualreferent, and 5 concept-referent; the others did not meet the criteria for a specific set.

To determine the stability of these characteristic response sets, the average $\mathrm{z}$ scores derived from responses on the second testing 1 week later were examined. These results are shown in Table 1.

\section{RESULTS AND DISCUSSION}

It is quite clear from the results shown in Table 1 that elderly individuals exhibited the same enduring free word association response sets found in the earlier study of children. The exact probability of predicting the largest values in the diagonal, as in Table 1, was .037. For the total sample of 32 , the retest Pearson correlation

Table 1

Standard Scores of Elderly with Response Set, After 1 Week

\begin{tabular}{crrrr}
\hline \multirow{2}{*}{$\begin{array}{c}\text { Set at First } \\
\text { Test }\end{array}$} & $\mathrm{N}$ & \multicolumn{3}{c}{ Average Standard Score 1 Week Later } \\
\cline { 2 - 5 } & \multicolumn{1}{c}{$\mathrm{D}$} & $\mathrm{P}$ & \multicolumn{1}{c}{$\mathrm{C}$} \\
\hline $\mathrm{D}$ & 12 & .81 & -.56 & -.30 \\
$\mathrm{P}$ & 4 & -1.41 & 2.03 & .09 \\
$\mathrm{C}$ & 5 & -.59 & -.24 & 1.44 \\
\hline
\end{tabular}

Note $-D=$ dimension-referent $; \quad P=$ perceptual-referent $; \quad C=$ concept-referent. 
coefficients for dimension-referent, perceptual-referent, and concept-referent were $.86, .63$, and .76 , respectively $(\mathrm{p}<.01)$.

These retest correlation coefficients were substantially larger than those reported earlier for the samples of children. Whether this increased predictability of response sets of elderly persons was due to interval between retest ( 1 week vs. 1 year) or to age of the subjects remains undetermined. The results are definitive, however, with respect to the presence of the same stable characteristic differences in cognitive dictionary structures in very elderly persons as those found in much younger ones. Moreover, as was true of all the younger samples, although the response sets of the elderly were reliable, the majority of their specific word pairs on test and retest were different.
As it was concluded with the younger samples, enduring individual differences in elderly cognitive dictionaries "are represented better by hierarchies of association principles that differ in probability of use, rather than by hierarchies of specific word-word affinities" (Moran \& Swartz, 1970, p. 21).

\section{REFERENCES}

Moran, L. J. Generality of word-association response sets. Psychological Monographs, 1966, 80(4, Whole No. 612).

Moran, L. J., \& Swartz, J. D. Longitudinal study of cognitive dictionaries from ages nine to seventeen. Developmental Psychology, 1970, 3, 21-28.

(Received for publication October 8, 1980.) 